COBEOSO

\title{
DETERMINAÇÃO EXPERIMENTAL DA CINÉTICA DE SECAGEM DO MORANGO.
}

\author{
I.R. JORGE ${ }^{1}$; M.B. SILVA ${ }^{1}$ \\ ${ }^{1}$ Universidade Federal do Triângulo Mineiro, Departamento de Engenharia Química \\ E-mail para contato: isabellajorge@hotmail.com
}

\begin{abstract}
RESUMO - O morango é conhecido e produzido por todo o mundo por ser um fruto atrativo e valorizado, ser fonte de vitaminas e nutrientes, o tornando a espécie de maior expressão econômica entre as pequenas frutas e com uma alta demanda. $\mathrm{O}$ consumo desse fruto acontece das mais diversas formas, o que faz com que alternativas para seu armazenamento sejam estudadas. $\mathrm{O}$ objetivo desse trabalho foi estudar a cinética de secagem do morango, através da variação da temperatura $\left(80^{\circ} \mathrm{C}\right.$ e $\left.90^{\circ} \mathrm{C}\right)$ e da forma geométrica (cúbica e cilíndrica), utilizando a balança medidora de umidade através de infravermelho, visando o ajuste dos dados experimentais aos modelos da literatura. A temperatura de secagem apresentou maior influência quando comparado à geometria do morango. O processo foi mais eficiente utilizando a temperatura de $90^{\circ} \mathrm{C}$ e a forma cúbica. O modelo logarítmico foi o que melhor se ajustou aos dados experimentais, apresentando $\mathrm{R}^{2}$ maior que $99 \%$ e DQM menor que 0,0170 para todos os casos.
\end{abstract}

\section{INTRODUÇÃO}

Conhecido e produzido por todo o mundo, o morango é um fruto atrativo e valorizado, isto acontece por ser um alimento nutritivo, o qual é fonte de vitamina $\mathrm{C}$, potássio, cálcio e magnésio, dentre outros nutrientes, o que o torna a espécie de maior expressão econômica entre as pequenas frutas e exige uma alta demanda (MACAN, 2013).

Eles são consumidos in natura ou podem ser aplicados em vários processos industriais como a fabricação de iogurtes, sucos, geleias, bolos, etc. Porém, a comercialização dos frutos in natura tem como principal limitante a rápida perda de qualidade, o que se deve ao alto teor de umidade, que pode atingir 90-95\% da parte comestível, segundo Gebhardt et al. (2002). Campo (2012) cita que a vida útil do morango fresco é de aproximadamente 5 dias quando mantido a baixas temperaturas $\left(0\right.$ a $\left.4^{\circ} \mathrm{C}\right)$.

Entretanto, para o armazenamento prolongado, somente a redução da temperatura não é suficiente para manter a qualidade dos frutos, sendo necessário utilizar técnicas complementares, visando ao prolongamento da sua vida útil (MALGARIM et al., 2006). 
A utilização da técnica de secagem para garantir a qualidade dos alimentos é muito comum nos mais diversos processos industriais. Essa é uma das operações unitárias mais antigas e usuais, onde o processo reduz a umidade para melhorar as características de armazenamento e manuseio do produto, conter a proliferação de microrganismos, diminuir ou bloquear a ação de enzimas que podem provocar alteração, concentrar maior quantidade de nutrientes nos alimentos e, reduzir o custo de frete, pois com a evaporação da água há uma redução de peso em torno de $50 \%$ a $80 \%$.

Segundo, McCabe et al. (2005), é na superfície do material que ocorre a evaporação da água, a qual foi transportada do interior do sólido. Os mecanismos mais importantes desse transporte são: difusão líquida, difusão de vapor e fluxo de líquido e de vapor. O conhecimento do conteúdo inicial e final (equilíbrio) de umidade do material, da relação da água com a estrutura sólida e do transporte da água do interior do material até a sua superfície possibilitam fundamentar o fenômeno da secagem.

Para a secagem de uma quantidade de alimentos em escala industrial, é imprescindível a simulação em uma escala piloto, para que os custos da operação, os quais estão relacionados, principalmente, com volume, velocidade de secagem e temperatura do ar, sejam conhecidos e assim maximizar os benefícios possíveis e/ou, minimizar ao máximo inevitáveis e irreversíveis perdas que podem ocorrer e, com isso, obter o sucesso do processo. Sendo assim, o objetivo desse trabalho é estudar a cinética de secagem do morango, através da variação da temperatura e da forma geométrica, utilizando a balança medidora de umidade através de infravermelho, visando o ajuste dos dados experimentais aos modelos da literatura.

\section{MATERIAIS E MÉTODOS}

\subsection{Preparação do Morango:}

Os morangos utilizados no experimento foram comprados no supermercado da cidade de Uberaba-MG, e para a utilização nos experimentos realizados, esses foram lavados com água corrente e secos logo em seguida com papel absorvente.

Após este procedimento, os frutos foram cortados com a utilização de uma faca inox em duas geometrias diferentes, cubo e cilíndrica, de forma que estas apresentassem um valor aproximado de volume igual a $8 \mathrm{~cm}^{3}$, com as dimensões medidas por um paquímetro, afim de comparar a influência dessa variável no processo de secagem.

Por fim, foram separadas e pesadas quatro amostras de $34,5 \mathrm{~g}$ cada, para que fosse possível distribuir de maneira eficiente na bandeja metálica da balança medidora de umidade através de infravermelho.

\subsection{Processo de Secagem:}


$\mathrm{O}$ teor de água inicial que existia nos morangos foi determinado pelo método gravimétrico, utilizando-se estufa à $105^{\circ} \mathrm{C}$, durante $24 \mathrm{~h}$, com três repetições, de acordo com (INSTITUTO ADOLFO LUTZ, 1985). As amostras apresentaram 92,91\% de umidade inicial, o que está de acordo com a literatura estudada, pois Venencio (2010) encontrou um valor de umidade inicial de $93,3 \%$.

A segunda etapa foi o estudo da influência de duas variáveis do processo, a temperatura de secagem e a forma geométrica do morango. Os valores utilizados foram de $80^{\circ} \mathrm{C}$ e $90^{\circ} \mathrm{C}$ para a temperatura, já que essas são possíveis de serem reproduzidas na indústria e também porque segundo Verbeyst et. al (2010), a partir de $95^{\circ} \mathrm{C}$ a degradação do morango se intensifica. Já as formas geométricas escolhidas foram a cilíndrica e a cúbica. Portanto foram realizados 4 experimentos na balança medidora de umidade através de infravermelho.

Durante a secagem verificou-se a porcentagem de umidade na amostra a cada 1 minuto, e esse valor foi analisado a partir da massa inicial, até que o equilíbrio fosse atingido.

\subsection{Curva de Secagem e Estudo da Cinética de Secagem}

Foi possível a construção da curva de secagem e o ajuste aos modelos matemáticos de secagem da literatura, conforme apresentados na Tabela 1 a seguir, utilizando os dados obtidos no experimento.

Tabela 1 - Modelos Cinéticos de Secagem

\begin{tabular}{cc}
\hline \multicolumn{2}{c}{ Modelos } \\
\hline Page & R.U. $=\exp ^{-k * t^{n}}$ \\
Newton & R.U. $=\exp ^{-k * t}$ \\
Henderson \& Pabis & R.U. $=a * \exp ^{-k * t}$ \\
Logaritimico & R.U. $=a * \exp ^{-k * t}+c$ \\
\hline
\end{tabular}

A curva de secagem representa a diminuição do teor de água do produto durante o processo. Para isso, utilizou a umidade, $\mathrm{U}$, em cada intervalo de tempo, fornecida pelo próprio aparelho e o Software Excel 2010.

Para o ajuste dos dados de secagem aos modelos matemáticos para o estudo da cinética de secagem, foi necessário calcular a razão de umidade (R.U.), através da Eq. (1) a seguir, a qual é um termo adimensional, e a utilização do Software STATISTICA 7.0®. 


$$
\text { R.U. }=\frac{m-m_{e q}}{m_{o}-m_{e q}}
$$

Onde, $m$ se refere à massa da amostra no tempo $t ; m_{e q}$ é a massa quando a amostra atinge o equilíbrio e $m_{o}$ é a massa inicial da amostra.

\section{RESULTADOS E DISCUSSÕES}

Os resultados obtidos do experimento de secagem são apresentados na Figura 1.

Figura 1- Curvas de Secagem

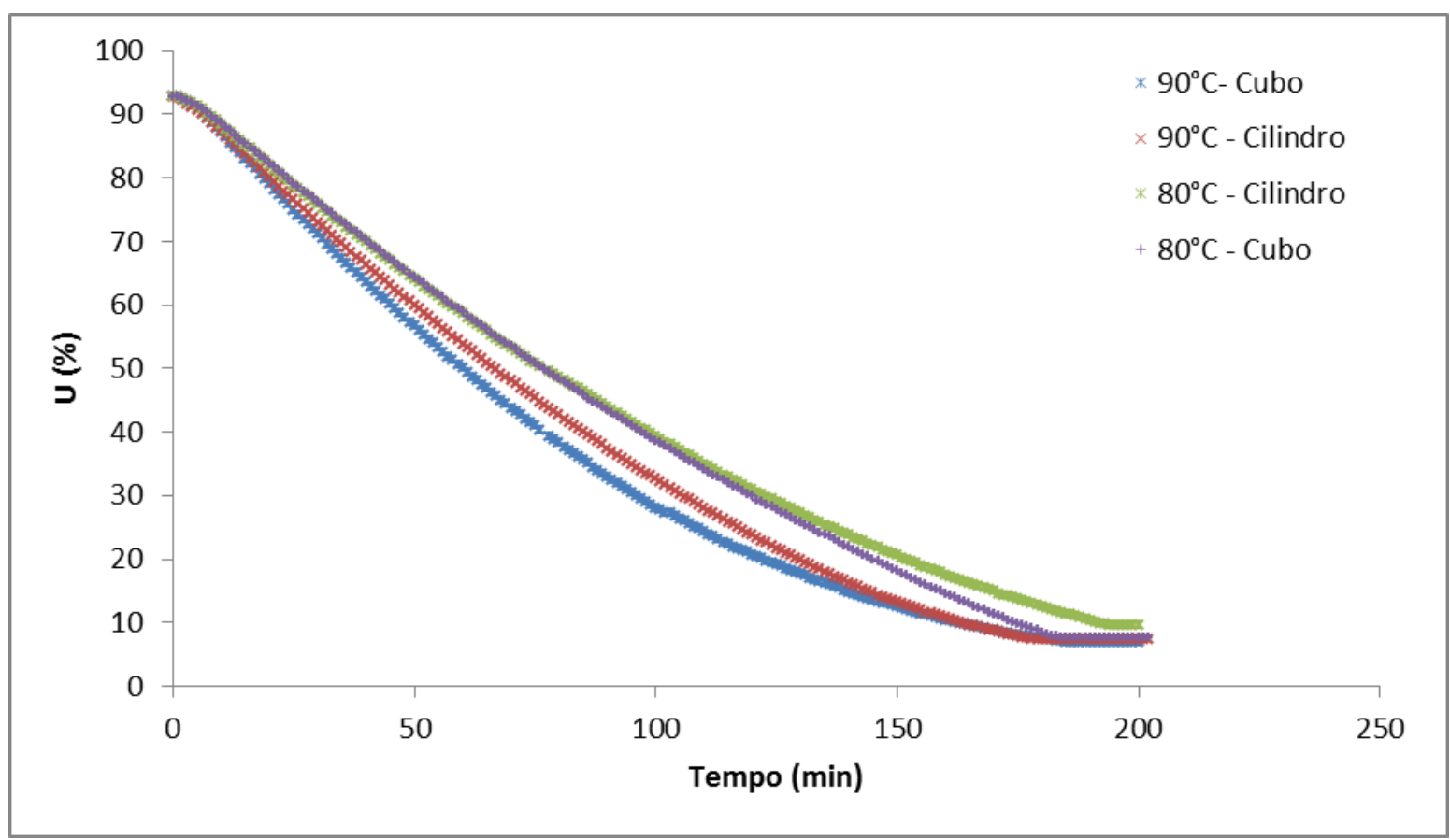

A partir da Figura 1, é possível visualizar os efeitos das variáveis no processo de secagem de morangos. Nota-se que na temperatura de $90^{\circ} \mathrm{C}$, para as duas geometrias, o teor de água diminuiu mais rapidamente, o que já era esperado, pois uma maior temperatura suaviza o tempo de secagem.

Analisando a influência da geometria, observa-se que o cubo apresentou maior velocidade de secagem em relação ao cilindro, o que pode ser explicado pela maior facilidade do calor em atingir as quatro faces dessa geometria, enquanto que no cilindro o infravermelho atingiu apenas uma superfície diretamente.

Porém as curvas de secagem ficaram muito próximas umas das outras. Uma análise com um intervalo maior de temperatura poderia evidenciar melhor os efeitos das variáveis. É 
possível observar que o fator temperatura teve uma influência maior que o fator geometria, visto que as curvas de geometrias diferentes com a mesma temperatura ficaram muito próximas, para $90^{\circ} \mathrm{C}$, e coincidiram por quase todo o tempo para $80^{\circ} \mathrm{C}$.

Para produtos biológicos, o comportamento de secagem é, geralmente, decrescente. Esse comportamento é determinado pela migração interna de umidade (BENDLIN, 2003). Portanto, provavelmente, a difusão é o mecanismo físico que governa o movimento da água no fruto.

Venencio (2010) também estudou a curva de secagem do morango e obteve um comportamento decrescente, semelhante ao descrito na Figura 1, o que mostra que no início a perda de umidade acontece rapidamente e ao longo do processo diminui até se estabilizar.

A cinética de secagem foi estudada através dos modelos matemáticos já citados anteriormente e os resultados para cada um estão apresentados nas Tabela 2 e 3 , a seguir.

Utilizando os valores de $\mathrm{R}^{2}$ e desvio quadrático médio (DQM) como critério de comparação entre os modelos, observa-se que o modelo Logarítmico foi o que melhor se ajustou, pois ele apresentou o maior $\mathrm{R}^{2}$, que representa uma medida do ajustamento do modelo aos dados experimentais, e o menor DQM, significando maior poder explicativo do modelo, para todos os casos.

A análise dos modelos cinéticos permite prever o comportamento do processo de secagem, o que é muito válido para a indústria, já que tal processo não é genérico. Assim, é possível afirmar que a cinética de secagem do morango pode ser prevista pelo modelo Logarítmico, já que este apresentou um valor de $\mathrm{R}^{2}$ elevado, maior que $99 \%$, e DQM menor que 0,0170 .

Tabela 2 - Ajustes dos modelos matemáticos para o cubo.

\begin{tabular}{ccccccc}
\hline & \multicolumn{7}{c}{ Cubo } \\
\hline & $\mathbf{8 0}^{\circ} \mathbf{C}$ & \multicolumn{5}{c}{$\mathbf{9 0}^{\circ} \mathbf{C}$} \\
\hline Modelos & $\mathbf{R}^{\mathbf{2}}$ & $\mathbf{D Q M}$ & Parâmetros & $\mathbf{R}^{\mathbf{2}}$ & $\mathbf{D Q M}$ & Parâmetros \\
\hline Page & 0,9937 & 0,0244 & $\mathrm{k}=0,0014$ & 0,9973 & 0,0162 & $\mathrm{k}=0,0023$ \\
& & & $\mathrm{n}=1,4477$ & & & $\mathrm{n}=1,4032$ \\
Newton & 0,9519 & 0,0684 & $\mathrm{k}=0,0109$ & 0,9635 & 0,0593 & $\mathrm{k}=0,0135$ \\
Henderson \& Pabis & 0,9692 & 0,0546 & $\mathrm{a}=1,1223$ & 0,9789 & 0,0451 & $\mathrm{a}=1,1264$ \\
& & & $\mathrm{k}=0,0124$ & & & $\mathrm{k}=0,0152$ \\
Logarítmico & 0,9995 & 0,0086 & $\mathrm{a}=1,5699$ & 0,9979 & 0,0142 & $\mathrm{a}=1,2728$ \\
& & & $\mathrm{k}=0,0056$ & & & $\mathrm{k}=0,0098$ \\
& & & $\mathrm{c}=-0,5368$ & & & $\mathrm{c}=-0,2149$ \\
\hline
\end{tabular}


Tabela 3- Ajustes dos modelos matemáticos para o cilindro.

\begin{tabular}{ccccccc}
\hline & \multicolumn{7}{c}{ Cilindro } \\
\hline & $\mathbf{8 0}^{\circ} \mathbf{C}$ & \multicolumn{5}{c}{$\mathbf{9 0}^{\circ} \mathbf{C}$} \\
\hline Modelos & $\mathbf{R}^{\mathbf{2}}$ & $\mathbf{D Q M}$ & Parâmetros & $\mathbf{R}^{\mathbf{2}}$ & $\mathbf{D Q M}$ & Parâmetros \\
\hline Page & 0,9909 & 0,0300 & $\mathrm{k}=0,0009$ & 0,9948 & 0,0226 & $\mathrm{k}=0,0016$ \\
& & & $\mathrm{n}=1,5254$ & & & $\mathrm{n}=1,4478$ \\
Newton & 0,9394 & 0,0775 & $\mathrm{k}=0,0109$ & 0,9547 & 0,0663 & $\mathrm{k}=0,0123$ \\
Henderson \& Pabis & 0,9597 & 0,0632 & $\mathrm{a}=1,1361$ & 0,9709 & 0,0531 & $\mathrm{a}=1,1257$ \\
& & & $\mathrm{k}=0,0125$ & & & $\mathrm{k}=0,0138$ \\
Logarítmico & 0,9985 & 0,0122 & $\mathrm{a}=1,7051$ & 0,9971 & 0,0169 & $\mathrm{a}=1,3777$ \\
& & & $\mathrm{k}=0,0050$ & & & $\mathrm{k}=0,0077$ \\
& & & $\mathrm{c}=0,6689$ & & & $\mathrm{c}=-0,3320$ \\
\hline
\end{tabular}

\section{CONCLUSÃO}

A temperatura de secagem apresentou maior influência quando comparado à geometria do morango. Assim, obteve-se um processo mais eficiente utilizando a temperatura de $90^{\circ} \mathrm{C}$ e a forma geométrica cúbica. $\mathrm{O}$ modelo logarítmico se ajustou bem aos dados experimentais, apresentando $\mathrm{R}^{2}$ maior que $99 \%$ e $\mathrm{DQM}$ menor que 0,0170 , o que permite prever o comportamento e estudar a cinética do morango através de tal modelo.

\section{REFERÊNCIAS BIBLIOGRÁFICAS}

BENDLIN, R. C. S. Secagem convectiva de erva-mate. 2003. Dissertação (Mestrado em Engenharia de Alimentos)-Departamento de Engenharia Química e de Alimentos, Universidade Federal de Santa Catarina, Florianópolis, 2003.

INSTITUTO ADOLFO LUTZ. Normas analíticas, métodos químicos e físicos para análise de alimentos. São Paulo,1985.

MCCABE, W. L.; SMITH, J.C.; HARRIOTT, P. Unit operations of chemical engineering. $7^{\text {th }}$ Ed. Boston: McGraw-Hill, 2005.

MACAN, L. R. Avaliação físico-química. Curso de Tecnologia em Alimentos, Universidade do Extremo Sul Catarinense, Criciúma, 2013.

VENENCIO, G. Avaliação da degradação pelargonidina. Instituto de Ciência e Tecnologia de Alimentos, Universidade Federal do Rio Grande do Sul, Porto Alegre, 2010.

VERBEYST, L.; OEY, I.; PLANCKEN, I.V.; HENDRICKX, M.; LOE, A. V. Kinetic study. Food Chemistry. Bélgica. v. 123, n.2, p.269-274,2010. 